\title{
THE INFLUENCE OF AGEING PROCESS ON THE BARIUM ALUMINATE PHASE COMPOSITION
}

\author{
A. O. Bezmaternykh ${ }^{1,}{ }^{*}, Y$. B. Shvaljov ${ }^{1}, V$. N. Kudiiarov ${ }^{1}, V$. E. Gubin ${ }^{1}$, and $M$. N. \\ Babihina $^{1}$ \\ ${ }^{1}$ National Research Tomsk Polytechnic University, 634050 Tomsk, Russia
}

\begin{abstract}
Barium aluminates were formed by the continuous precipitation method at different values of $\mathrm{pH}$. The influence of ageing process and precipitation $\mathrm{pH}$ on the phase composition of the precipitate after firing was found. It was showed that there is growth of the $3 \mathrm{BaOAl}_{2} \mathrm{O}_{3}$ concentration after ageing of precipitate during 7 days. Presumably, this process is associated with a decrease in the number of crystals, increasing their size in the ageing process of precipitate and chemical processes that occur during ageing: hydrolysis, hydration, dehydration.
\end{abstract}

\section{Introduction}

Dispenser cathodes are widely used in most electronic devices. Dispenser cathode is a cathode which is based on a porous sponge made of refractory metal. Tungsten powder is often used as the sponge material. The sponge pores are filled by the active substance to complete saturation of them. Mixture of barium oxide compounds with the acid or amphoteric oxides of some elements is the active substance. The operating principle of the cathode is based on the active substance interaction with metal of the sponge (reducing agent), thereby forming free barium, which activates the cathode.

Recently, technologies for obtaining chemically pure substances [1-3] found wide application. The classical method for preparing active substance is firing of barium carbonate with calcium carbonate and aluminum oxide (fig. 1a). However, this method has significant drawbacks. The products synthesized in this way are not sufficiently pure and have particle size heterogeneity.

In [4], the method for obtaining active substances was used by coprecipitation components, which formed barium-calcium aluminates and barium-calcium tungstates at subsequent firing of the precipitate. This technique has several advantages: rapidity of the reaction, the minimum amount of impurities. However, the disadvantage of this method is a batch process for the implementation of the process, leading to instability and poor reproducibility of the quality characteristics of the finished product.

\footnotetext{
*Corresponding author: Upenikova@yandex.ru
} 
We propose to eliminate these drawbacks by the use of continuous precipitation technology at constant $\mathrm{pH}$. This technique allows obtaining a substance with the desired final characteristics.

Furthermore, the precipitate final characteristics largely depend on precipitation parameters such as the concentration of the initial solutions, the value of $\mathrm{pH}$, precipitation temperature, ageing time and temperature of the washing liquid.

In this paper we explored the effect of precipitation $\mathrm{pH}$ and ageing process on the formation of the final phase composition of the precipitate after firing.

a)

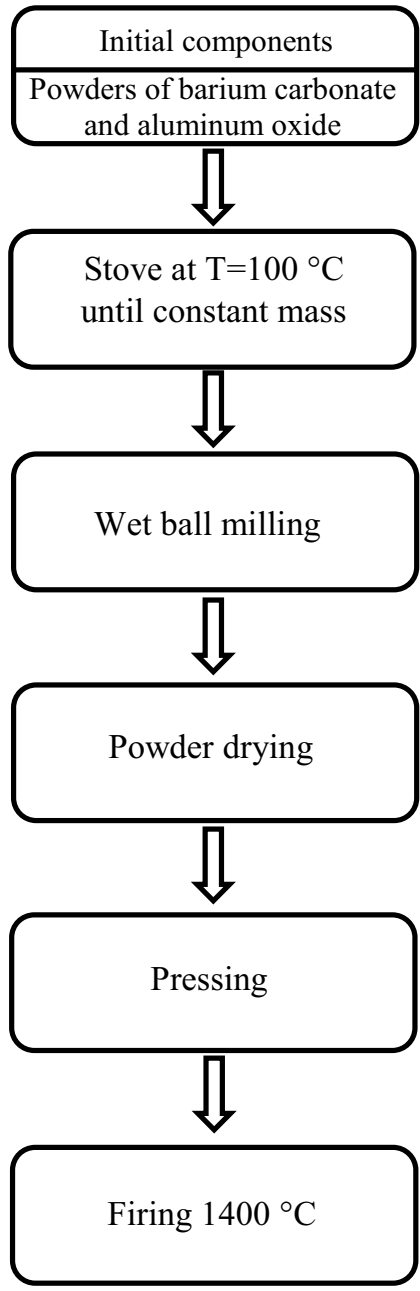

b)

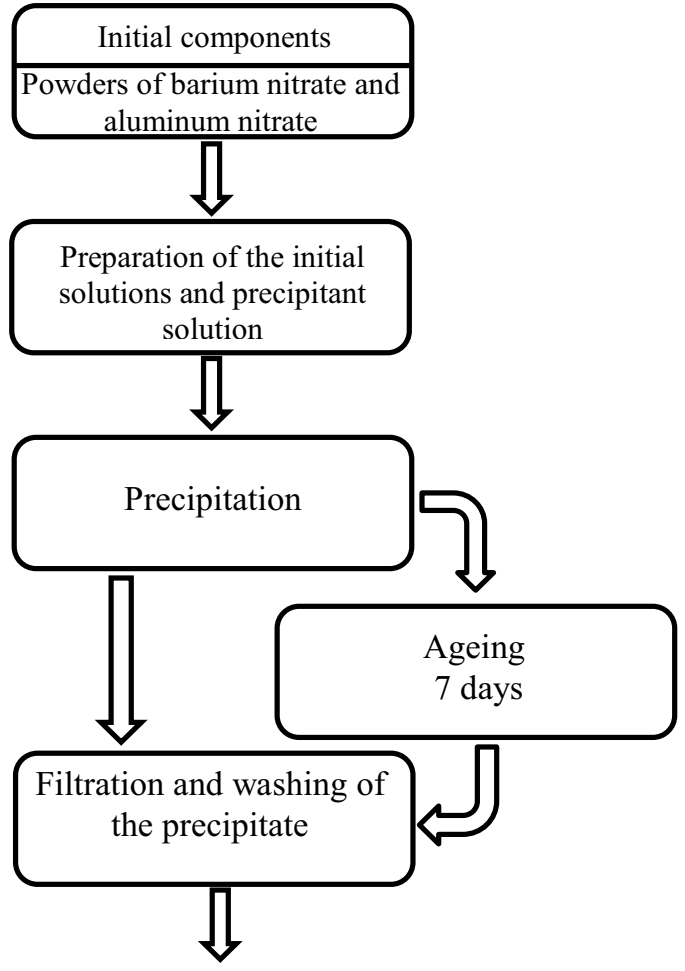

Stove at $\mathrm{T}=110^{\circ} \mathrm{C}$ until constant mass

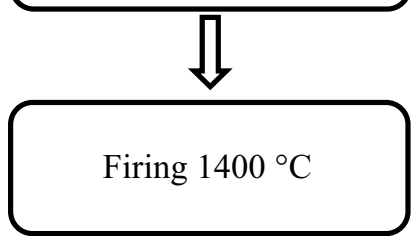

Fig. 1. The scheme of the barium aluminates synthesis a) classical technology b) precipitation method.

\section{Materials and Methods}

Initial solution of barium nitrate salts and aluminum was used for barium aluminates synthesis. Sodium carbonate solution acted as a precipitator. Data shown on the phase diagram [5] (fig. 2) was used for calculating the concentrations of the solutions. 


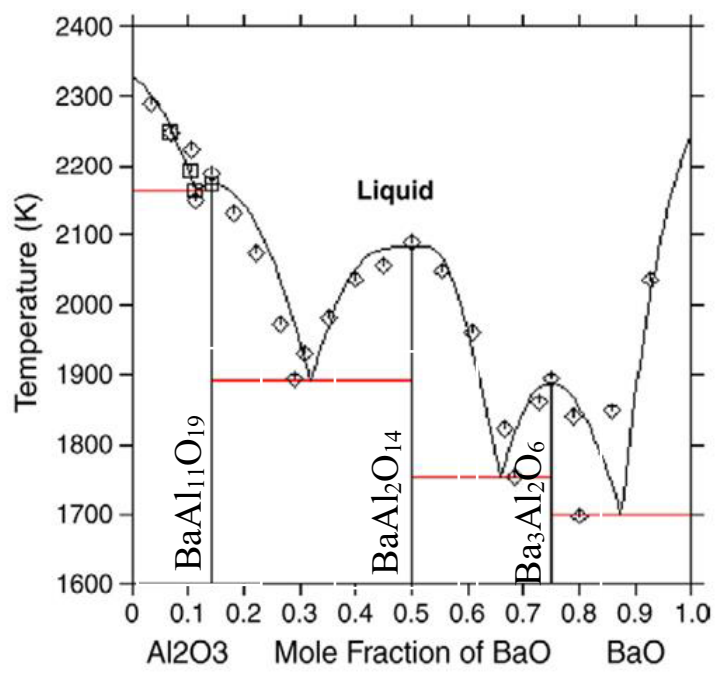

Fig. 2. Constitution diagram $\mathrm{Al}_{2} \mathrm{O}_{3}-\mathrm{BaO}[5]$.

Phase composition of the precipitate after firing was obtained by the XRD method on the Shimadzu XRD-7000S diffractometer. The following parameters were used during the experiment: scan speed $-2^{\circ}$ per minute; scanning step $-0.03^{\circ}$; range of angles $-20-50^{\circ} ; 1.5$ seconds for information accumulation. The average crystallite size was determined using the Debye-Scherrer equation from the broadening of the diffraction peaks, taking into account the instrumental broadening and software PowderCell 2.4.

\section{The Experimental Procedure}

The preparation of the active substances was performed on the experimental facility which was previously successfully applied in the preparation of catalysts and sorbents of medical immunobiological drugs [6]. The scheme of experimental facility is shown in fig. 2. The construction of the experimental setup makes possible precipitation in periodic and continuous modes, at constant or variable volume, variable and constant $\mathrm{pH}$, and different temperatures.

Solutions of aluminum nitrate and barium nitrate and sodium carbonate with given concentrations were supplied from tanks $(1,2)$ to the reactor $(6)$ through the thermostat $(5)$ by peristaltic pumps $(3,4)$. Precipitation was carried out at room temperature. Stirring was carried out using a mechanical stirrer (8). $\mathrm{PH}$ values were determined by $\mathrm{pH}$-meter (9); electrodes are installed directly in the reactor. Adjustment and maintenance of the $\mathrm{pH}$ value was carried by changing the rate of sodium carbonate supplying. Formed precipitate was supplied into collector (11) by pump (10).

Precipitation was done at three values of $\mathrm{pH}: 6.5,7.0,7.5$. Part of samples was kept in the mother liquor at room temperature during 7 days. The precipitate was washed to a negative reaction to an anion $\mathrm{NO}^{3-}$. After washing in distilled water the precipitate was dried to constant weight at temperature of $110^{\circ} \mathrm{C}$. Then the process of firing was done for precipitate at temperature of $1400{ }^{\circ} \mathrm{C}$ during 2 hours. Brief scheme of the experiment is shown in figure $1 \mathrm{~b}$. 


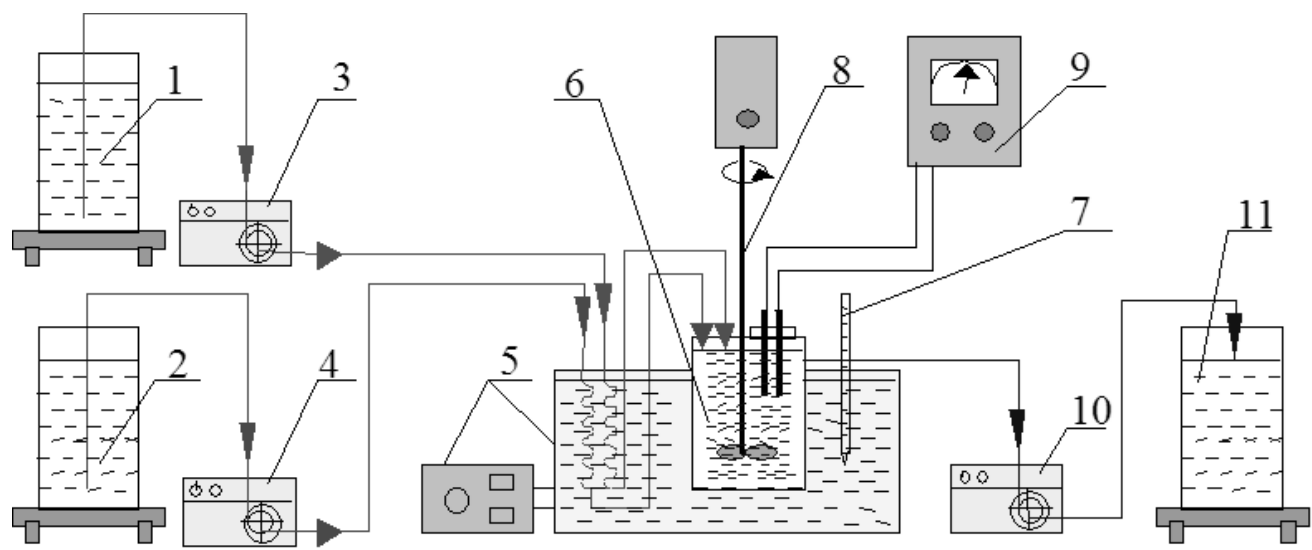

Fig. 3. The scheme of experimental facility: $1-$ tank with a solution of barium nitrate and aluminum nitrate, 2 - tank with a solution of sodium carbonate, 3,4 - peristaltic pumps, 5 - thermostat, 6 - reactor, 7 - thermometer, 8 - mechanical stirrer, 9 - pH-meter, 10 - pump, 11 - collector.

\section{Results and Discussion}

The results of XRD analysis of the barium aluminate are shown in the Table 1.

Table 1. The results of the barium aluminate XRD analysis.

\begin{tabular}{|c|c|c|c|c|c|}
\hline \multirow[b]{2}{*}{ No. } & \multicolumn{2}{|c|}{ Conditions } & \multirow[b]{2}{*}{ Phases } & \multirow{2}{*}{$\begin{array}{l}\text { Phases } \\
\text { volume } \\
\text { content.\% }\end{array}$} & \multirow{2}{*}{$\begin{array}{c}\text { Lattice } \\
\text { parameters, } \\
\text { A }\end{array}$} \\
\hline & $\begin{array}{l}\mathrm{pH}, \\
\text { values }\end{array}$ & Ageing time, days & & & \\
\hline \multirow[t]{2}{*}{1} & \multirow{4}{*}{6.5} & \multirow[t]{2}{*}{ - } & $\mathrm{BaAl}_{2} \mathrm{O}_{4}$ & 86.7 & $\begin{array}{l}\mathrm{a}=5.2263 \\
\mathrm{c}=8.7933\end{array}$ \\
\hline & & & $\mathrm{Ba}_{3} \mathrm{Al}_{2} \mathrm{O}_{6}$ & 13.3 & $\mathrm{a}=16.5199$ \\
\hline \multirow[t]{2}{*}{2} & & \multirow[t]{2}{*}{7} & $\mathrm{BaAl}_{2} \mathrm{O}_{4}$ & 57.9 & $\begin{array}{l}a=5.2231 \\
c=8.7939\end{array}$ \\
\hline & & & $\mathrm{Ba}_{3} \mathrm{Al}_{2} \mathrm{O}_{6}$ & 42.1 & $\mathrm{a}=16.5144$ \\
\hline \multirow[t]{2}{*}{3} & \multirow{4}{*}{7.0} & \multirow[t]{2}{*}{ - } & $\mathrm{BaAl}_{2} \mathrm{O}_{4}$ & 74.7 & $\begin{array}{l}a=5.2243 \\
c=8.7975\end{array}$ \\
\hline & & & $\mathrm{Ba}_{3} \mathrm{Al}_{2} \mathrm{O}_{6}$ & 25.3 & $\mathrm{a}=16.5041$ \\
\hline \multirow[t]{2}{*}{4} & & \multirow[t]{2}{*}{7} & $\mathrm{BaAl}_{2} \mathrm{O}_{4}$ & 38.8 & $\begin{array}{l}a=5.2224 \\
c=8.7944\end{array}$ \\
\hline & & & $\mathrm{Ba}_{3} \mathrm{Al}_{2} \mathrm{O}_{6}$ & 61.2 & $\mathrm{a}=16.5133$ \\
\hline \multirow[t]{2}{*}{5} & \multirow{4}{*}{7.5} & \multirow[t]{2}{*}{ - } & $\mathrm{BaAl}_{2} \mathrm{O}_{4}$ & 79.8 & $\begin{array}{l}\mathrm{a}=5.2206 \\
\mathrm{c}=8.7893\end{array}$ \\
\hline & & & $\mathrm{Ba}_{3} \mathrm{Al}_{2} \mathrm{O}_{6}$ & 20.2 & $\mathrm{a}=16.4984$ \\
\hline \multirow[t]{2}{*}{6} & & \multirow[t]{2}{*}{7} & $\mathrm{BaAl}_{2} \mathrm{O}_{4}$ & 17.7 & $\begin{array}{l}\mathrm{a}=5.2070 \\
\mathrm{c}=8.7879\end{array}$ \\
\hline & & & $\mathrm{Ba}_{3} \mathrm{Al}_{2} \mathrm{O}_{6}$ & 82.3 & $\mathrm{a}=16.4941$ \\
\hline
\end{tabular}

It should be noted that the mainly dominates monoaluminate barium in the materials obtained at a given $\mathrm{pH}$ and not subjected to aging. The change of $\mathrm{pH}$ does not influence the phase composition of the precipitate after firing. 
Stage of ageing, which is allowed to proceed for 7 days, has a significant impact on the phase composition of the precipitate after firing. For example, at $\mathrm{pH} 6.5,7.0$ and 7.5 , there is an increase of $3 \mathrm{BaOAl} 2 \mathrm{O} 3$ content on $28.8 \%, 25.3 \%$ and $62.1 \%$ respectively compared with precipitate after firing obtained by the same value of $\mathrm{pH}$, but do not subjected to the ageing process.

It can be assumed that this process is related to physical and chemical phenomena occurring during ageing, such as the improvement of the structure of crystals, desorption of contaminants trapped in the precipitation process, as well as enlargement of the primary crystals.

Furthermore, there are possibly chemical processes in the precipitate when it stored under a layer of mother liquor. These chemical processes lead to changes in chemical and physical properties of the precipitate and in its chemical composition. Possible to assume that some processes such as hydrolysis, hydration and dehydration occur during the ageing processes of precipitate, which cause the increase the content of $3 \mathrm{BaOAl} 2 \mathrm{O} 6$ in the material after firing.

\section{Conclusion}

Barium aluminates were formed by the continuous precipitation method at different values of $\mathrm{pH}$. The influence of ageing process and precipitation $\mathrm{pH}$ on the phase composition of the precipitate after firing was found. It was showed that there is growth of the $3 \mathrm{BaOAl} 2 \mathrm{O} 3$ concentration after ageing of precipitate during 7 days. Presumably, this process is associated with a decrease in the number of crystals, increasing their size in the ageing process of precipitate and chemical processes that occur during ageing: hydrolysis, hydration, dehydration.

\section{Acknowledgements}

This work was funded within the framework of realisation of Strategic Programme on National Research Tomsk Polytechnic University Competitiveness Enhancement in the Group of Top Level World Research and Academic Institutions.

\section{References}

1. C. Higashi, N.B. De Lima, J.R. Matos, C. Giovedi, C.C. Motta, Proc. IMOC (2005)

2. Q Wang, W. Liu, L. Dong, X. Zhu, X. Liu, J. Wang. Proc. IVEC (2015)

3. F.F. Sene, V.O. Santos, C.C. Motta, IVESC (2012)

4. A.A. Maklakov, E.P. Ostapchenko, J. Struct. Chem. 1 (1960)

5. X. Ye, W. Zhuang, C. Deng, W. Yuan, Z. Qiao, CALPHAD. 30 (2006)

6. L.D. Bystritskii, N.N. Dolzhenko, N.H. Stavitskaya, E.V. Stepanova, D.E. Sharygin, Y.B. Shvalev, RF Patent 2171678, A61K33/08. (2001) 